See discussions, stats, and author profiles for this publication at: https://www.researchgate.net/publication/317258454

\title{
Efficacy of Laser Photobiomodulation on Morphological and Functional Repair of the Facial Nerve
}

Article in Photomedicine and Laser Surgery · May 2017

DOI: $10.1089 /$ pho.2016.4204

CITATIONS

6

11 authors, including:

Daniela Buchaim

Universidade de Marília

37 PUBLICATIONS 98 CITATIONS

SEE PROFILE

Benedito Barraviera

São Paulo State University

230 PUBLICATIONS 1,519 CITATIONS

SEE PROFILE

Some of the authors of this publication are also working on these related projects:

Journal of Venomous Animals and Toxins including Tropical Diseases View project

Project Infiltrative myelopathy by paracoccidioidomycosis View project
READS

176

Rui Seabra Ferreira Jr

São Paulo State University

114 PUBLICATIONS 754 CITATIONS

SEE PROFILE

Antonio de Castro Rodrigues

University of São Paulo

69 PUBLICATIONS 761 CITATIONS

SEE PROFILE 


\title{
Efficacy of Laser Photobiomodulation on Morphological and Functional Repair of the Facial Nerve
}

\author{
Daniela Vieira Buchaim, PhD, Jesus Carlos Andreo, $\mathrm{PhD}$, Rui Seabra Ferreira Junior, $\mathrm{PhD}{ }^{3}$ \\ Benedito Barraviera, $\mathrm{PhD}^{3}$, Antonio de Castro Rodrigues, $\mathrm{PhD}^{2}$, Mariana de Cássia Macedo, BS, \\ Geraldo Marco Rosa Junior, $\mathrm{PhD}^{4}$, Andre Luis Shinohara, PhD, Iris Jasmin Santos German, MS, \\ Karina Torres Pomini, MS, and Rogerio Leone Buchaim, $\mathrm{PhD}^{2}$
}

\begin{abstract}
Objective: Evaluate the efficacy of low-level laser therapy (LLLT) on qualitative, quantitative, and functional aspects in the facial nerve regeneration process. Materials and methods: Forty-two male Wistar rats were used, randomly divided into a control group (CG; $n=10)$, in which the facial nerve without lesion was collected, and four experimental groups: (1) suture experimental group (SEG) and (2) fibrin experimental group (FEG), consisting of 16 animals in which the buccal branch of the facial nerve was sectioned on both sides of the face; an end-to-end epineural suture was performed on the right side, and a fibrin sealant was used on the left side for coaptation of the stumps; and (3) laser suture experimental group (LSEG) and (4) laser fibrin experimental group (LFEG), consisting of 16 animals that underwent the same surgical procedures as SEG and FEG with the addition of laser application at three different points along the surgical site (pulsed laser of $830 \mathrm{~nm}$ wavelength, optical output power of $30 \mathrm{~mW}$, power density of $0.2586 \mathrm{~W} / \mathrm{cm}^{2}$, energy density of $6.2 \mathrm{~J} / \mathrm{cm}^{2}$, beam area of $0.116 \mathrm{~cm}^{2}$, exposure time of $24 \mathrm{sec}$ per point, total energy per session of $2.16 \mathrm{~J}$, and cumulative dose of $34.56 \mathrm{~J}$ ). The animals were submitted to functional analysis (subjective observation of whisker movement) and the data obtained were compared using Fisher's exact test. Euthanasia was performed at 5 and 10 weeks postoperative. The total number and density of regenerated axons were analyzed using the unpaired $t$-test $(p<0.05)$. Results: Laser therapy resulted in a significant increase in the number and density of regenerated axons. The LSEG and LFEG presented better scores in functional analysis in comparison with the SEG and FEG. Conclusions: LLLT enhanced axonal regeneration and accelerated functional recovery of the whiskers, and both repair techniques allowed the growth of axons.
\end{abstract}

Keywords: lasers in dentistry, low-level laser therapy, nerve regeneration, peripheral nerve injury, tissue regeneration and healing

\section{Introduction}

$\mathbf{P}$ ERIPHERAL NERVE TRAUMAS caused by both crushing and sectioning are common, resulting in reduction or loss of sensory and motor functions in the innervated area. ${ }^{1}$ Injuries involving the facial nerve, which is responsible for the maintenance and dynamics of facial expression muscles, are clinically important as the resulting social and functional problems lead to a significant reduction in quality of life..$^{2,3}$

Peripheral facial palsy may be caused by trauma, accidental injuries, viral infections, inflammations, metabolic diseases, and tumors. The incidence of this condition is 20 30 cases in 100,000 individuals. It may lead to complications in verbal communication through facial expressions, which are very important in social relationships. ${ }^{4-9}$

Injuries involving peripheral nerves are classified, according to Seddon (1943), functionally and anatomically into neuropraxia, axonotmesis, and neurotmesis. ${ }^{10}$ In 1951, Sunderland described five types of nerve lesions: the first type corresponds to neurapraxia and the second to axonotmesis. The third, fourth, and fifth types involve injury, respectively, to endoneurial tubes, perineurium, and epineurium. ${ }^{11}$

\footnotetext{
${ }^{1}$ Human Morphophysiology (Anatomy), University of Marília (UNIMAR), Marília, Brazil.

${ }^{2}$ Department of Biological Sciences (Anatomy), Bauru School of Dentistry, University of São Paulo, Bauru, Brazil.

${ }^{3}$ Center for the Study of Venoms and Venomous Animals, São Paulo State University (UNESP-Univ Estadual Paulista), Botucatu, Brazil.

${ }^{4}$ Health Sciences Center, University of the Sacred Heart, Bauru, Brazil.
} 
Depending on the type of injury, the peripheral nerves may present regenerative capacity by themselves or through the use of surgical techniques, such as in the case of neurotic injuries, in which the nerve suffers total sectioning of the axon and its surroundings. ${ }^{12,13}$ For neurotimic and small extension injuries, end-to-end epineural neurorrhaphy, where the stumps may be approximated and sutured without exaggerated tension, is considered the gold standard. ${ }^{14,15}$

However, neurorrhaphy techniques that use sutures require knowledge of microsurgical techniques and the functional damage that can result from excessive manipulation of tissues. ${ }^{16,17}$ Fibrin sealant is currently used in the recovery of peripheral nerves with the aim of minimizing the disadvantages of epineural suture techniques. ${ }^{18}$

The new heterologous fibrin sealant derived from snake venom is a biological and biodegradable product containing no human blood, preventing the spread of infectious diseases. It also has good adhesive capacity and is used as an adjunct to conventional suture procedures. ${ }^{19}$ The clot formed by the fibrin sealant is a physiological component found in the repair of tissues, differing from that of other types of sealants that present high fibrin formation and toxicity. The fibrin sealant can be a useful tool in the clinical environment as it presents high versatility and reduced cost in comparison with commercial adhesives. ${ }^{20}$

Low-level laser therapy (LLLT) is another modality used in the process of regeneration and functional recovery of peripheral nerves. It was first used in the 1980s and has been the subject of numerous recent studies because it demonstrates an immediate protective effect, reducing the formation of edema and scar tissue in the region of the injury and increasing axonal metabolism. ${ }^{21,22}$ In addition, it has analgesic and anti-inflammatory properties and increases mitotic activity, leading to a faster nerve regeneration process. ${ }^{23,24}$

The photobiostimulatory effect of LLLT refers to a tissue uptake by photoreceptors, thus facilitating mitochondrial respiration, adenosine triphosphate production, additional calcium transport in the cytoplasm, and initiation of signaling pathways mediated by reactive oxygen species, the cyclic adenosine monophosphate and nitric oxide. ${ }^{25}$ These effects lead to activation of several transcription factors related to cell migration, proliferation, survival, tissue repair, and nerve regeneration. ${ }^{26}$

Functional evaluation of the repair of nerve injuries usually complements morphological evaluations. In rats, one method is the evaluation of movements of the whiskers through its position and movement. The movement without tremors and the anterior positioning of the whiskers generally serve as reference for the analysis of postinjury recovery. ${ }^{27,28}$

Because of the way in which it is currently produced, the new heterologous fibrin sealant has not been subjected to functional testing on facial nerve lesions. Taking into account the incidence of nerve injuries and their functional and social effects, the present study aimed to evaluate the efficacy of LLLT on qualitative, quantitative, and functional aspects of the facial nerve regeneration process.

\section{Materials and Methods}

\section{Experimental design}

The experimental procedures were approved by the Animal Ethics Committee of the School of Dentistry of Bauru of the University of São Paulo (São Paulo, Brazil).
Forty-two 60-day-old male Wistar rats (Rattus norvegicus) with an average weight of 250 grams were used. All animals were kept in appropriate boxes and received water and food ad libitum with no movement restrictions, maintaining a 12-h light-12-h dark regime (temperature of $\sim 22^{\circ} \mathrm{C}$ ).

The animals were randomly divided into a control group (CG) and four experimental groups:

1. CG consisted of 10 animals in which the buccal branch of the facial nerve was collected at 95 and 130 days, the euthanasia times of the experimental groups.

2. Suture experimental group (SEG) and fibrin experimental group (FEG) consisted of 16 animals in which the buccal branch of the facial nerve was sectioned on both sides of the face; end-to-end epineural suture was performed on the right side, and fibrin sealant was used on the left side for coaptation of the stumps. The animals were euthanized 5 weeks (95 days old) and 10 weeks after the surgery (130 days old).

3. Laser suture experimental group (LSEG) and laser fibrin experimental group (LFEG) consisted of 16 animals that underwent the same surgical procedures as SEG and FEG in combination with the application of LLLT. The animals were euthanized 5 weeks (95 days old) and 10 weeks after the surgery (130 days old).

\section{Experimental surgery}

For the surgical procedure, at the of age of 60 days, all of the animals in the experimental groups (SEG, FEG, LSEG, and LFEG) were weighed and submitted to general anesthesia by intramuscular injection of the anesthetic agent Zoletil 50 (Virbac, Brazil) in the following proportion: 1:1 (125:125 mg) tiletamine hydrochloride and zolazepam hydrochloride $(0.15 \mathrm{~mL} / \mathrm{kg} / \mathrm{IM})$. After adoption of antisepsis techniques for the procedure, trichotomy was performed on all of the animals and they were placed in the lateral decubitus position.

A facial incision was performed with a No. 15 scalpel blade (approximately from the tragus of the ear to the corner of the mouth) with subsequent dissection by layers up to the exposure of the buccal branch of the facial nerve (Fig. 1A). The nerve was sectioned with fine straight tip Íris surgical scissors (Quinelato; Rio Claro, Brazil) without removal of fragments (Fig. 1B).

In the SEG group, an end-to-end epineural suture was performed on the right side of the face with 10/0 monofilament nylon sutures (Ethicon; Johnson \& Johnson, Brazil; Fig. 1C). In the FEG group, following the same procedure, the stumps were approximated and coaptated with the fibrin sealant (Fig. 1D). Completing the surgical procedure, the skin was sutured with 4-0 silk thread (Ethicon; Johnson \& Johnson).

\section{Fibrin sealant}

A new heterologous fibrin sealant derived from snake venom was kindly supplied by the Center for the Study of Venoms and Venomous Animals of São Paulo State University; its constituents and instructions for use are stated in its patents (registration numbers BR1020140114327 and BR1020140114360) and it was prepared as suggested by Barros et al. ${ }^{19}$ The components of the sealant were stored in three Eppendorf tubes and kept at $-80^{\circ} \mathrm{C}$. At the time of use, the components were thawed, then reconstituted, mixed, and 

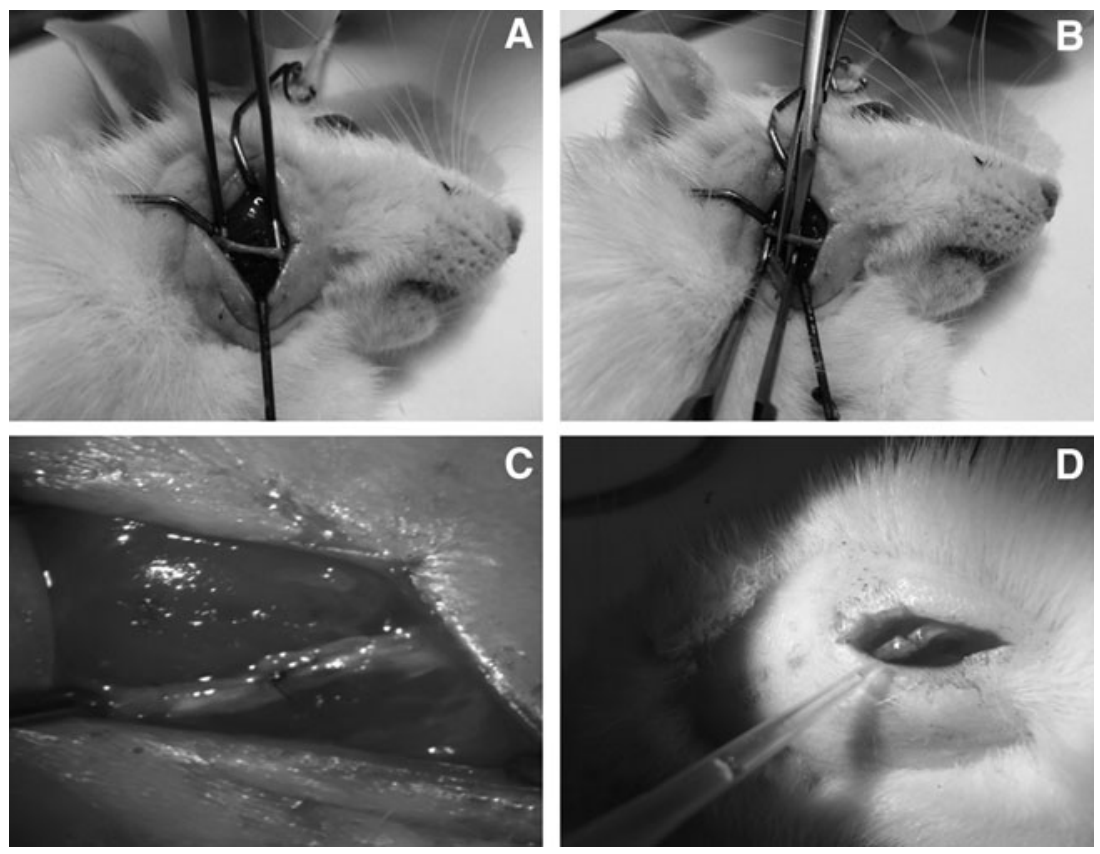

FIG. 1. Experimental surgery: (A) incision of the skin and exposure of the buccal branch of the facial nerve, (B) sectioning of the buccal branch of the facial nerve, (C) end-to-end epineural suture, and (D) coaptation with fibrin sealant. applied according to the following protocol: the first bottle contained fibrinogen obtained from buffalo blood $(5 \mu \mathrm{L})$, the second contained calcium chloride $(2 \mu \mathrm{L})$, and the third contained a thrombin-like fraction $(1 \mu \mathrm{L})$, totaling $8 \mu \mathrm{L} .^{19,20,29-31}$

\section{Photobiomodulation therapy}

In the LSEG and LFEG groups, the animals were subjected to photobiomodulation (PBM) therapy with a continuous pulse from a gallium-aluminum-arsenide laser (GaAlAs; Laserpulse IBRAMED, São Paulo, Brazil). The protocol was applied using a laser pen on the skin surface, with the following parameters ${ }^{32,33}$ :

- Wavelength: $830 \mathrm{~nm}$

- Optical output power: $30 \mathrm{~mW}$

- Power density: $0.2586 \mathrm{~W} / \mathrm{cm}^{2}$

- Energy density: $6.2 \mathrm{~J} / \mathrm{cm}^{2}$

- Beam area: $0.116 \mathrm{~cm}^{2}$

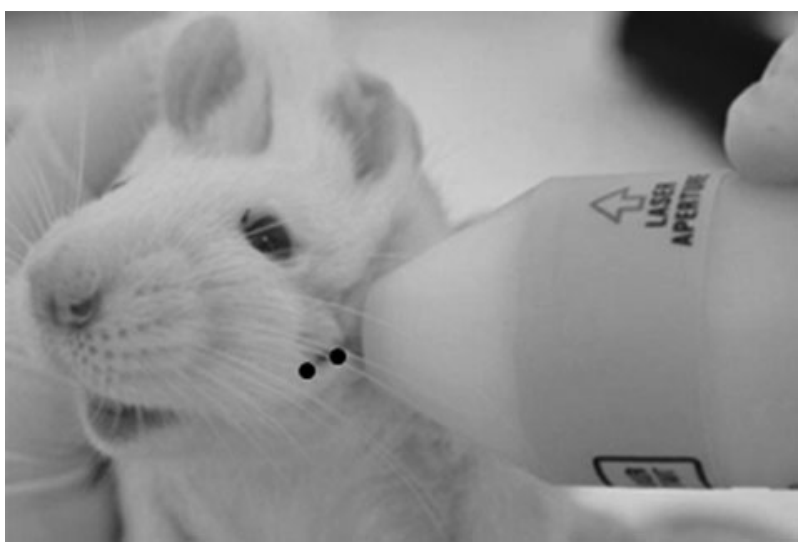

FIG. 2. Positioning of the laser pen over the surgical area. Application at the caudal point of the incision, with cranial and midpoint markings (black circle).
- Exposure time: $24 \mathrm{sec}$ per point

- Three different points along the surgical site

- Total energy per point: $0.72 \mathrm{~J}$

- Total energy per session: $2.16 \mathrm{~J}$

- Cumulative dose: $34.56 \mathrm{~J}$

The laser source had previously been tested to verify the dose. The laser therapy applications were performed 1 day after surgery and three times a week in the postoperative period for a total of 5 weeks. ${ }^{34-38}$ For the application, the animals were carefully restrained by placing the operator's hand firmly over the back and rib cage. The laser pen was placed over the incision area, in three points: cranial, middle, and caudal, in relation to the cranial delimitation plane (Fig. 2).

\section{Functional analysis}

During the postsurgical period, the animals were submitted to observation of facial movement, spontaneously and under stimulation. Each rat was individually assessed twice, at the 5th and 10th weeks, in a cardboard box with a black inner surface to provide more clarity in the observation of whisker movement. The observer clapped his palms together three or four times to generate better whisker movement. This observation was made by the same examiner and all of the animals were photographed and filmed for more efficient data collection. The observer classified the

Table 1. Scale of Observation of the Whiskers ACCORDING TO FARIA ET AL. ${ }^{27}$

\begin{tabular}{lll}
\hline Score & \multicolumn{1}{c}{ Movement } & Position \\
\hline 1 & No movement & Posterior \\
2 & Light tremor & Posterior \\
3 & Major tremor & Posterior \\
4 & Normal movement & Posterior \\
5 & Normal movement & Anterior \\
\hline
\end{tabular}



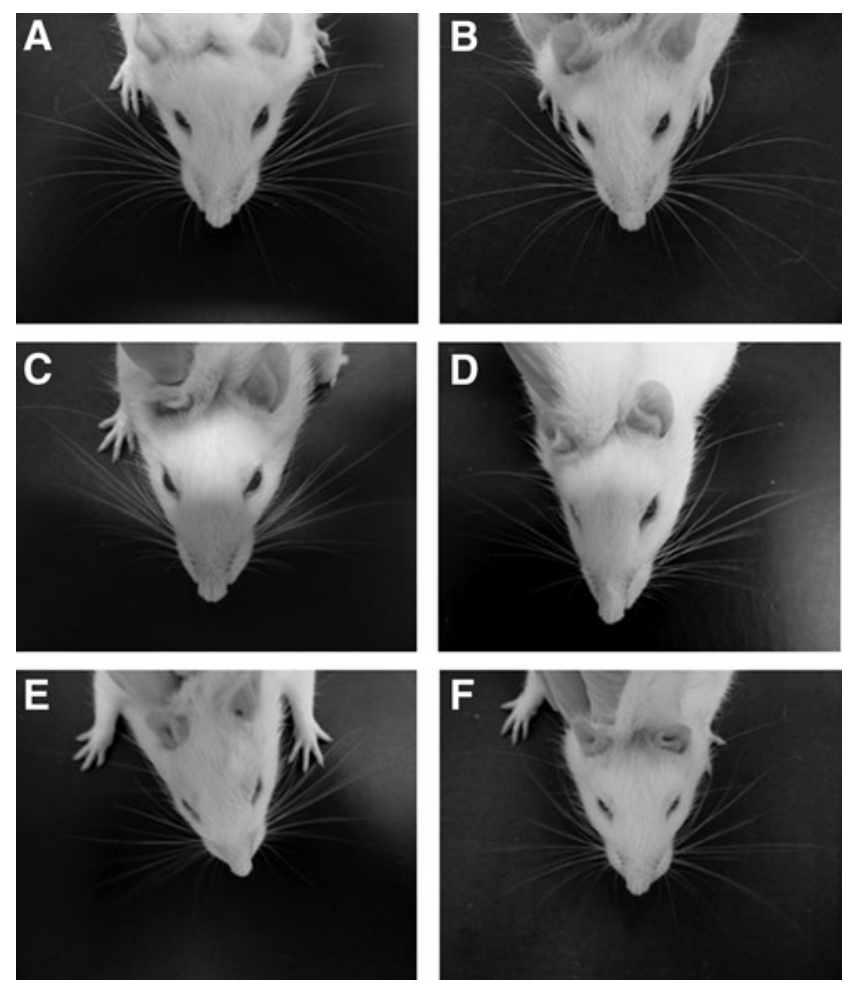

FIG. 3. (A) CG at 5 weeks and (B) CG at 10 weeks: animals presenting normal whisker movement and anterior position; (C) SEG (right side of the face) and FEG (left side of the face), animals at 5 weeks, movement with major tremor and posterior position; (D) LSEG (right side of the face) and LFEG (left side of the face), animals at 5 weeks, normal movement and posterior position; (E) SEG (right side of the face) and FEG (left side of the face), animals at 10 weeks, normal movement and posterior position; (F) LSEG (right side of the face) and LFEG (left side of the face), animals at 10 weeks, normal movement and anterior position. CG, control group; FEG, fibrin experimental group; LFEG, laser fibrin experimental group; LSEG, laser suture experimental group; SEG, suture experimental group.

whisker movement according to the scale below, as described by Faria et al. ${ }^{27}$ (Table 1).

\section{Euthanasia and histological processing}

At 5 and 10 weeks after the surgical procedure, 5 animals from the CG and 16 animals from the experimental groups were euthanized by anesthetic overdose. The previously operated site was reopened to capture images of the nerve stumps using a digital microscope (Dino Lite Plus, Taiwan) and to collect the undamaged buccal branch of the facial nerve in the CG and the distal stump from the buccal branch of the facial nerve in animals from the experimental groups (SEG, FEG, LSEG, and LFEG).

The samples were fixed in Karnovsky's solution for $24 \mathrm{~h}$ and then immersed for $2 \mathrm{~h}$ in $1 \%$ osmium tetroxide (SigmaAldrich, USA). Then, the sections were subjected to routine procedures for inclusion in histological resin (Leica Historesin, Germany). After inclusion, ultrathin transverse sections $(5 \mu \mathrm{m})$ of the fascicles were obtained and stained with $1 \%$ toluidine blue. The images were captured using an Olympus microscope (Japan) and photographs were taken with a coupled digital camera (Olympus DP 71, Japan).

\section{Quantitative analysis of regenerated axons}

Quantitative evaluation of regenerated axons in the distal stump of the buccal branch of the facial nerve was performed in the experimental groups with three images obtained with 400x magnification, involving analysis of the total number of myelinated axons in a $9000 \mu \mathrm{m}^{2}$ nerve area and the partial density of myelinated axons [partial number of axons/partial area $\left.\left(9000 \mu \mathrm{m}^{2}\right)\right]$, according to Bento et al. ${ }^{39}$

\section{Statistical analysis}

The data obtained from whisker movement were compared using Fisher's exact test. ${ }^{28}$ Quantitative analysis was carried out using Image Pro-Plus 6.0 software (Media Cybernetics, Bethesda, MD). The total number and density of regenerated axons were analyzed using the unpaired $t$-test (significance level $\alpha<0.05$ ) once normality was demonstrated (Shapiro-Wilks test), and comparisons were between groups that had the same repair technique with or without LLLT $($ SEG $\times$ LSEG; FEG $\times$ LFEG) during the same period. The software program used for statistical analysis was GraphPad (La Jolla, CA).

\section{Results}

\section{Functional analysis}

The CG was used as a measure of normality in relation to the movement and position of the whiskers (score 5), according to the parameters established in Table 1 (Fig. 3A, B).
FIG. 4. Results of the functional analysis (whisker movement and position).
5 weeks
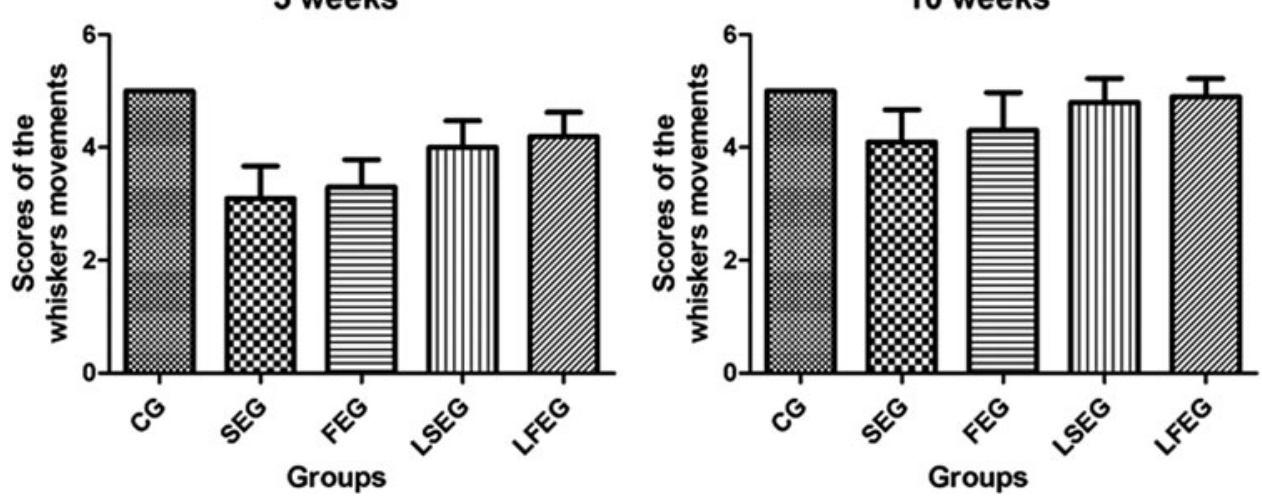

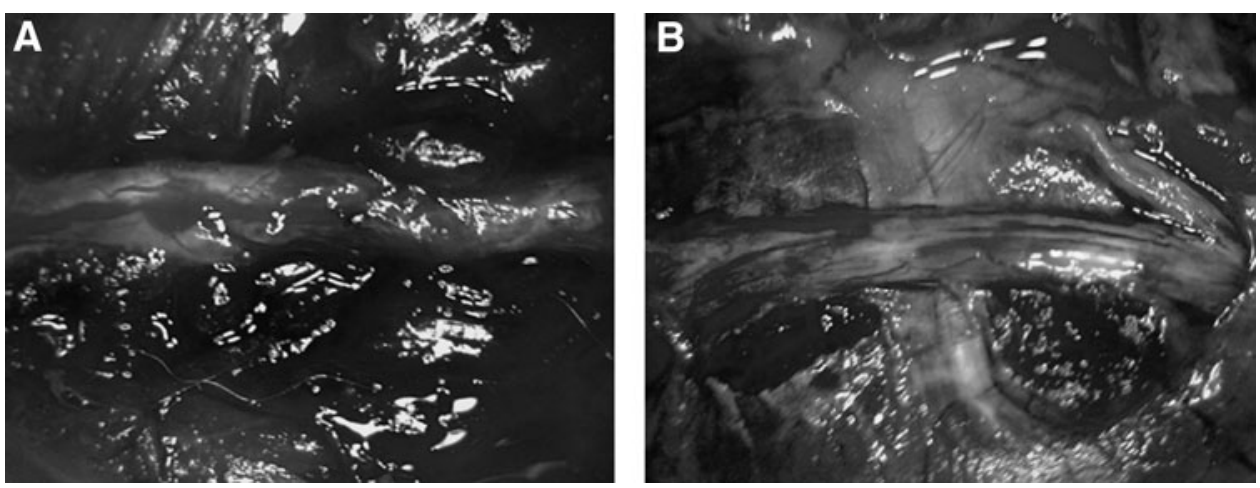

FIG. 5. (A) Proximal and distal nerve stumps reconnected by suture with $10-$ 0 nylon monofilament. (B) Proximal and distal stumps connected by fibrin sealant $(25 \mathrm{x}$ increase).

At 5 weeks, the SEG and FEG presented median scores of 3.1 and 3.3, respectively, representing movement with major tremor and posterior position (Fig. 3C). The LSEG and LFEG, which were submitted to LLLT, presented median scores of 4.0 and 4.2, respectively, corresponding to normal movement and posterior position (Fig. 3D).

At 10 weeks, the SEG and FEG presented median scores of 4.1 and 4.3, respectively, representing normal movement and posterior position (Fig. 3E). The LSEG and LFEG presented median scores of 4.8 and 4.9, respectively, with normal movement and anterior position, similar to the $\mathrm{CG}$ (Fig. 3F).

Figure 4 shows the scores for assessment of whisker movement and position in all animals of all groups in the assessed periods (mean and standard deviation).

\section{Morphological assessment (digital microscopy)}

In both analyzed periods, all of the animals presented nerve stumps fixed by suture or fibrin sealant (Fig. 5).

\section{Morphological assessment (optical microscopy)}

Five weeks after surgery, all animals in the CG presented myelinated fibers regularly arranged inside the nerve with regular morphology. The experimental groups presented myelinated fibers irregularly arranged with heterogeneous diameters distributed inside the nerve, adjacent connective tissue, and the presence of new blood vessels (Fig. 6).

Ten weeks after surgery, the CG presented myelinated fibers with regular appearance, similar to at 5 weeks postoperative. In the experimental groups, the myelinated fibers presented irregular arrangement and morphology distributed inside the nerve, adjacent connective tissue, and the presence of new blood vessels (Fig. 7).

\section{Quantitative assessment}

With regard to the number and density of regenerated axons, there was a statistically significant difference (significance level $\alpha<0.05$ ) between the groups (SEG $\times$ LSEG; FEG $\times$ LFEG; $p<0.0001)$ at both 5 weeks (Table 2) and 10 weeks (Table 3).

\section{Discussion}

The present study aimed to evaluate the efficacy of LLLT on qualitative, quantitative, and functional aspects of the facial nerve regeneration process. It was concluded that LLLT enhanced axonal regeneration and accelerated the functional recovery of whiskers and that both repair techniques (suture and a new heterologous fibrin sealant) promoted the growth of axons.

End-to-end epineural suture is described as an effective technique for axonal regeneration in cases of neurotimic
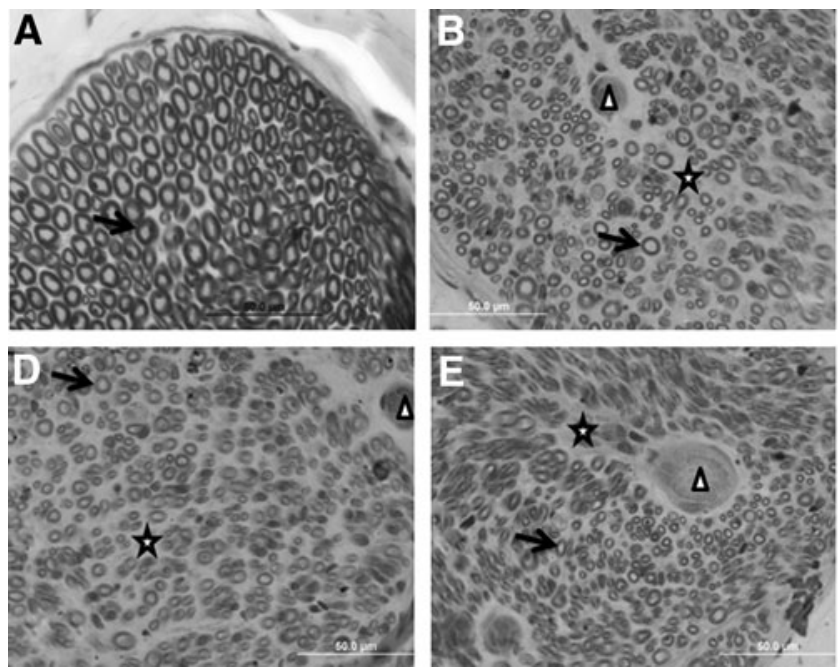

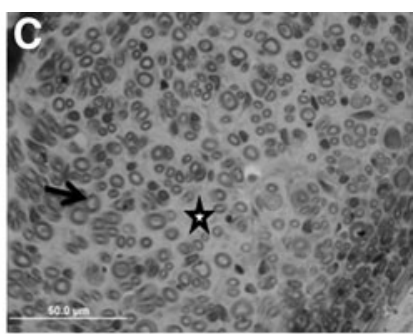

FIG. 6. Animals 5 weeks postsurgery. Microscopic appearance of the buccal branch of the facial nerve in the groups: (A) CG, (B) SEG, (C) FEG, (D) LSEG, and (E) LFEG. Presence of myelinated fibers (arrow), connective tissue (star), and blood vessels (triangle). 
FIG. 7. Animals at 10 weeks postsurgery. Microscopic appearance of the buccal branch of the facial nerve in the groups: (A) CG, (B) SEG, (C) FEG, (D) LSEG, and (E) LFEG. Presence of myelinated fibers (arrow), connective tissue (star), and blood vessels (triangle).
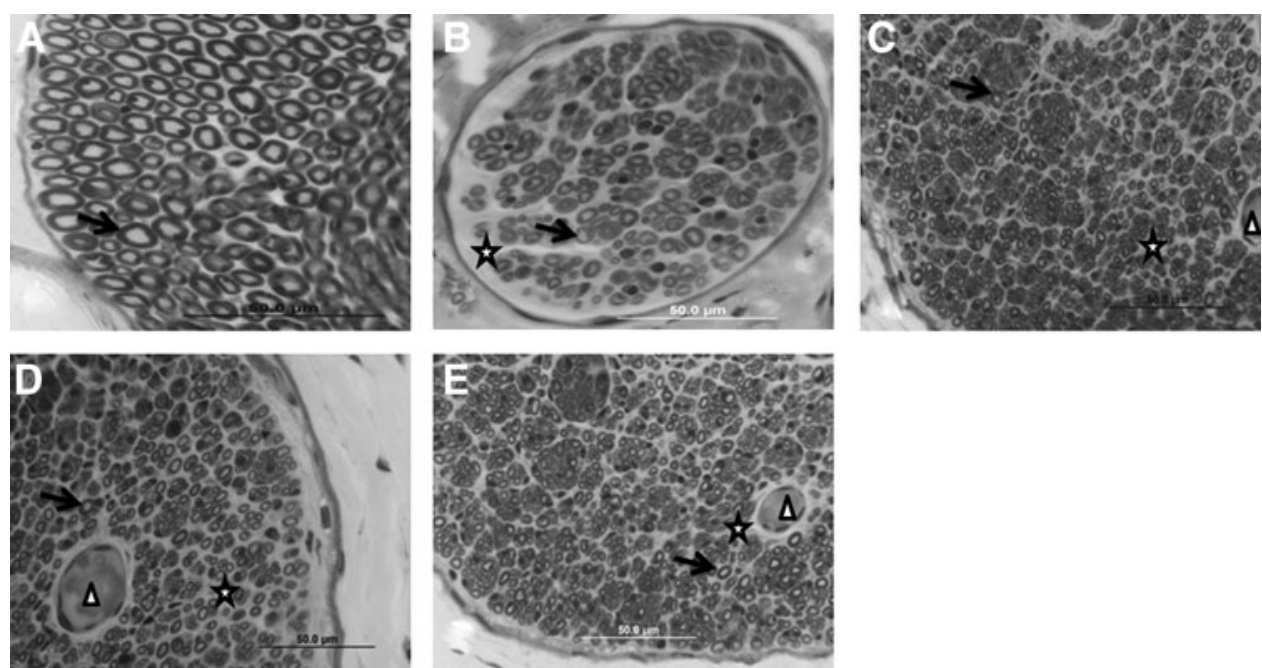

injuries that do not present tissue loss. ${ }^{14,15}$ In the present study, the buccal branch of the facial nerve was sectioned and the stumps were approximated without exaggerated tension. End-to-end suture was then performed, leading to satisfactory results that are in accordance with previous research, in which the end-to-end epineural suture technique is considered the gold standard in cases of full injuries of the nerve with small lengths and no tissue loss. ${ }^{14-16}$

However, according to some studies, the repair of injuries involving peripheral nerves by means of sutures includes stump manipulation, leading to disruption of the axons and consequent formation of fibrosis. ${ }^{40}$ In the search for an alternative technique or a technique that may be associated with suturing, fibrin sealants have been shown to be effective and their application is easier ${ }^{32,37,41-44}$; in addition, the surgery time for nerve repair is shorter. ${ }^{32,37}$ During surgical procedures, fibrin sealant has presented good adherence and manipulation properties, as observed in other nerve injury recovery work. ${ }^{19,29,37,42,43,45,46}$

In general, in all experimental groups, morphological observation presented a prevalence of myelinated fibers with irregular arrangement and diameters, showing that the nerve was in the process of regeneration. Consistent with these data, other research through histological analyses has shown no differences between the techniques. ${ }^{16,47}$ At 10 weeks postoperative, the nerve fascicles presented a better arrangement in relation to the myelinated fibers when compared with 5 weeks, showing a progressive trend in the experimental groups.

Regarding the use of LLLT in the process of repairing nerve injuries, studies using similar protocols have shown that laser light causes the expression of neurotrophic factors,

Table 2. Comparison of Number and Density of Axons in the Distal Stump of the Buccal Branch of the Facial Nerve (SEG $\times$ LSEG; FEG $\times$ LFEG) at 5 Weeks

\begin{tabular}{llcclcr}
\hline Axons & Groups & Mean value & SD & Groups & Mean value & $S D$ \\
\hline Number & SEG & $1.015^{\mathrm{a}}$ & 37.05 & FEG & $1.046^{\mathrm{a}}$ & 66.42 \\
& LSEG & $1.142^{\mathrm{b}}$ & 59.53 & LFEG & $1.248^{\mathrm{b}}$ & 65.42 \\
Density $\left(\right.$ number $\left./ \mu \mathrm{m}^{2}\right)$ & SEG & $0.1127^{\mathrm{a}}$ & 0.004 & FEG & $0.1162^{\mathrm{a}}$ & 0.007 \\
& LSEG & $0.1269^{\mathrm{b}}$ & 0.006 & LFEG & $0.1387^{\mathrm{b}}$ & 0.007
\end{tabular}

Different lowercase letters $(\mathrm{a}, \mathrm{b})$ indicate significant differences among the groups by mean $\pm \mathrm{SD}$, unpaired $t$-test, and significance level $\alpha<0.05, p<0.0001$.

FEG, fibrin experimental group; LFEG, laser fibrin experimental group; LSEG, laser suture experimental group; SD, standard deviation; SEG, suture experimental group.

Table 3. Comparison of Number and Density of Axons in the Distal Stump of the Buccal Branch of the Facial Nerve $($ SEG $\times$ LSEG; FEG $\times$ LFEG) at 10 WeEKS

\begin{tabular}{llcclcr}
\hline Axons & Groups & Mean value & SD & Groups & Mean value & $S D$ \\
\hline Number & SEG & $1.175^{\mathrm{a}}$ & 41.33 & FEG & $1.232^{\mathrm{a}}$ & 33.61 \\
& LSEG & $1.318^{\mathrm{b}}$ & 22.19 & LFEG & $1.397^{\mathrm{b}}$ & 10.61 \\
Density $\left(\right.$ number $\left./ \mu \mathrm{m}^{2}\right)$ & SEG & $0.1306^{\mathrm{a}}$ & 0.004 & FEG & $0.1369^{\mathrm{a}}$ & 0.004 \\
& LSEG & $0.1464^{\mathrm{b}}$ & 0.002 & LFEG & $0.1552^{\mathrm{b}}$ & 0.001 \\
\hline
\end{tabular}

Different lowercase letters $(\mathrm{a}, \mathrm{b})$ indicate significant differences among the groups by mean $\pm \mathrm{SD}$, unpaired $t$-test, and significance level $\alpha<0.05, p<0.0001$. 
leading to increased regenerative rates and contributing to reduced inflammation and edema. ${ }^{24,38}$ However, the parameters of irradiation, dosage, intensity, exposure time, and laser application methods vary widely among the different clinical reports on nerve regeneration. ${ }^{47}$

The application protocol used in this study was based on previous work carried out, which showed the beneficial effects of LLLT in the regenerative process in nerve repair as in bone repair with the use of gallium-aluminum-arsenide that (when used under appropriate conditions) has good penetration capacity in tissues, improving and speeding the recovery process of the injuries. ${ }^{32,33}$ Although the results of this study demonstrate the effectiveness of the laser, more research is needed for the standardization of protocols applied. $^{22,23,33,37,48,49}$

In facial nerve regeneration experiments, rats present anatomy that allows easy access to the nerve and ease of sectioning and repair, with subsequent functional analysis of whisker movement due to the dynamics of the animal justifying their choice for this experiment. These data are in agreement with the literature, demonstrating that it is possible to assess and quantify facial expressions from clinical observation using scoring scales. ${ }^{27,28}$

For analysis of whisker movement, we chose 5 weeks and 10 weeks after surgery for the analysis of functional progress according to maximum regeneration of the axons. ${ }^{50}$ The best results were found in the LSEG and LFEG at 10 weeks, with anterior position of the whiskers, similar to the CG, which is probably a consequence of the beneficial effects of laser therapy, the only difference in variable between the groups. The quantitative analysis, with higher averages and significant difference in the groups with LLLT, agreed with the functional assessment.

Electrophysiological tests may assist the functional assessment, which can be considered a limitation for this study. Further studies using other methodologies are recommended such as the new PBM therapy. In general, the buccal branch of the facial nerve reacts satisfactorily to both of the assessed techniques, and the LLLT promotes faster functional recovery of whisker movement, showing it to be a potential auxiliary alternative in the nerve regeneration process.

\section{Conclusions}

LLLT enhanced axonal regeneration and accelerated the functional recovery of whisker movement, and both repair techniques (suture and a new heterologous fibrin sealant) promoted the growth of axons.

\section{Author Disclosure Statement}

No competing financial interests exist.

\section{References}

1. Grinsell D, Keating CP. Peripheral nerve reconstruction after injury: a review of clinical and experimental therapies. Biomed Res Int 2014;2014:698256.

2. Birgfeld C, Neligan P. Surgical approaches to facial nerve deficits. Skull Base 2011;2:177-184.

3. Thorén H, Snäll J, Salo J, et al. Occurrence and types of associated injuries in patients with fractures of the facial bones. J Oral Maxillofac Surg 2010;68:805-810.
4. Krug EG, Sharma GK, Lozano R. The global burden of injuries. Am J Public Health 2000;90:523-526.

5. Atolini Junior N, Jorge Junior J, Gignon VF, Kitice AT, Prado LSA, Santos VGW. Facial nerve palsy: incidence of different etiologies in a tertiary ambulatory. Int Arch Otorhinolaryngol 2009;13:167-171.

6. Dougall A, Fiske J. Access to special care dentistry, part 9. Special care dentistry services for older people. Br Dent J 2008;205:421-434.

7. Tong Y, Chen J, Ji Q. A unified probabilistic framework for spontaneous facial action modeling and understanding. IEEE Trans Pattern Anal Mach Intell 2010;32:258-273.

8. Fattah A, Borschel GH, Zuker RM. Reconstruction of facial nerve injuries in children. J Craniofac Surg 2011;22:782-788.

9. Li J, Goldberg G, Munin MC, Wagner A, Zafonte R. Posttraumatic bilateral facial palsy: a case report and literature review. Brain Inj 2004;18:315-320.

10. Seddon HJ. Three types of nerve injury. Brain, Oxford 1943;66:237-288.

11. Sunderland S. A classification of peripheral nerve injuries producing loss of function. Brain 1951;74:491-516.

12. Friedman AH, Elias WJ, Midha R. Introduction: peripheral nerve surgery-biology, entrapment, and injuries. Neurosurg Focus 2009;26:E1.

13. Sinis N, Geuna S, Viterbo F. Translational research in peripheral nerve repair and regeneration. Biomed Res Int 2014;2014:381426.

14. Johnson EO, Soucacos PN. Nerve repair: experimental and clinical evaluation of biodegradable artificial nerve guides. Injury 2008;39(Suppl 3):S30-S36.

15. Ray WZ, Mackinnon SE. Management of nerve gaps: autografts, allografts, nerve transfers, and end-to-side neurorrhaphy. Exp Neurol 2010;223:77-85.

16. Attar BM, Zalzali H, Razavi M, Ghoreishian M, Rezaei M. Effectiveness of fibrin adhesive in facial nerve anastomosis in dogs compared with standard microsuturing technique. J Oral Maxillofac Surg 2012;70:2427-2432.

17. Tetik C, Ozer K, Ayhan S, Siemionow K, Browne E, Siemionow $\mathrm{M}$. Conventional versus epineural sleeve neurorrhaphy technique: functional and histomorphometric analysis. Ann Plast Surg 2002;49:397-403.

18. Egloff DV, Narakas A. Nerve anastomoses with human fibrin. Preliminary clinical report (56 cases). Ann Chir Main 1983;2:101-115.

19. Barros LC, Ferreira RS Jr, Barraviera SR, et al. A new fibrin sealant from Crotalus durissus terrificus venom: applications in medicine. J Toxicol Environ Health B Crit Rev 2009;12:553-571.

20. Ferreira RS. Autologous or heterologous fibrin sealant scaffold: which is the better choice? J Venom Anim Toxins Incl Trop Dis 2014;20:31.

21. Rochkind S, Leider-Trejo L, Nissan M, Shamir MH, Kharenko O, Alon M. Efficacy of 780-nm laser phototherapy on peripheral nerve regeneration after neurotube reconstruction procedure (double-blind randomized study). Photomed Laser Surg 2007;25:137-143.

22. Rochkind S, Geuna S, Shainberg A. Chapter 25: Phototherapy in peripheral nerve injury: effects on muscle preservation and nerve regeneration. Int Rev Neurobiol 2009; $87: 445-464$.

23. Lins RD, Dantas EM, Lucena KC, Catão MH, GranvilleGarcia AF, Carvalho Neto LG. Biostimulation effects of low-power laser in the repair process. An Bras Dermatol 2010;85:849-855. 
24. Akgul T, Gulsoy M, Gulcur HO. Effects of early and delayed laser application on nerve regeneration. Lasers Med Sci 2014;29:351-357.

25. Farivar S, Malekshahabi T, Shiari R. Biological effects of low level laser therapy. J Lasers Med Sci 2014;5:58-62.

26. Mohammed IF, Al-Mustawfi N, Kaka LN. Promotion of regenerative processes in injured peripheral nerve induced by low-level laser therapy. Photomed Laser Surg 2007;25: 107-111.

27. Faria SD, Testa JRG, Borin A, Toledo RN. Standardization of techniques used in facial nerve section and facial movement evaluation in rats. Rev Bras Otorrinolaringol 2006;72:341-347.

28. Farrag TY, Lehar M, Verhaegen P, Carson KA, Byrne PJ. Effect of platelet rich plasma and fibrin sealant on facial nerve regeneration in a rat model. Laryngoscope 2007;117: $157-165$.

29. Thomazini-Santos IA, Barraviera SRCS, Mendes-Giannini MJS, Barraviera B. Surgical adhesives. J Venom Anim Toxins 2001;7:159-171.

30. Barros LC, Soares AM, Costa FL, et al. Biochemical and biological evaluation of gyroxin isolated from Crotalus durissus terrificus venom. J Venom Anim Toxins Incl Trop Dis 2011;17:23-33.

31. Gasparotto VP, Landim-Alvarenga FC, Oliveira AL, et al. A new fibrin sealant as a three-dimensional scaffold candidate for mesenchymal stem cells. Stem Cell Res Ther 2014;5:78.

32. Buchaim DV, Rodrigues Ade C, Buchaim RL, et al. The new heterologous fibrin sealant in combination with lowlevel laser therapy (LLLT) in the repair of the buccal branch of the facial nerve. Lasers Med Sci 2016;3:965-972.

33. Oliveira Gonçalves JB, Buchaim DV, Souza Bueno CR, et al. Effects of low-level laser therapy on autogenous bone graft stabilized with a new heterologous fibrin sealant. J Photochem Photobiol B 2016;162:663-668.

34. Fazilat F, Ghoreishian M, Fekrazad R, Kalhori KA, Khalili SD, Pinheiro AL. Cellular effect of low-level laser therapy on the rate and quality of bone formation in mandibular distraction osteogenesis. Photomed Laser Surg 2014;32: 315-321.

35. Wang CZ, Chen YJ, Wang YH, et al. Low-level laser irradiation improves functional recovery and nerve regeneration in sciatic nerve crush rat injury model. PLoS One 201413;9:e103348.

36. Anders $\mathrm{JJ}$, Moges $\mathrm{H}, \mathrm{Wu} \mathrm{X}$, et al. In vitro and in vivo optimization of infrared laser treatment for injured peripheral nerves. Lasers Surg Med 2014;46:34-45.

37. Buchaim RL, Andreo JC, Barraviera B, et al. Effect of lowlevel laser therapy (LLLT) on peripheral nerve regeneration using fibrin glue derived from snake venom. Injury 2015; 46:655-660.

38. Gigo-Benato D, Geuna S, Rochkind S. Phototherapy for enhancing peripheral nerve repair: a review of the literature. Muscle Nerve 2005;31:694-701.

39. Bento RF, Salomone R, Nascimento SB, Ferreira RJ, Silva $\mathrm{CF}$, Costa HJ. Mandibular branch of the facial nerve in wistar rats: new experimental model to assess facial nerve regeneration. Int Arch Otorhinolaryngol 2014;18:277-282.
40. Sandrini FA, Pereira-Júnior ED, Gay-Escoda C. Rabbit facial nerve anastomosis with fibrin glue: nerve conduction velocity evaluation. Braz J Otorhinolaryngol 2007;73:196-201.

41. Whitlock EL, Kasukurthi R, Yan Y, Tung TH, Hunter DA, Mackinnon SE. Fibrin glue mitigates the learning curve of microneurosurgical repair. Microsurgery 2010;30:218-222.

42. Sameem M, Wood TJ, Bain JR. A systematic review on the use of fibrin glue for peripheral nerve repair. Plast Reconstr Surg 2011;127:2381-2390.

43. Barbizan R, Castro MV, Rodrigues AC, Barraviera B, Ferreira RS, Oliveira AL. Motor recovery and synaptic preservation after ventral root avulsion and repair with a fibrin sealant derived from snake venom. PLoS One 2013; 8:e63260.

44. Ahmad E, Fatima MT, Hoque M, Owais M, Saleemuddin M. Fibrin matrices: the versatile therapeutic delivery systems. Int J Biol Macromol 2015;81:121-136.

45. Machado EG, Issa JP, Figueiredo FA, et al. A new heterologous fibrin sealant as scaffold to recombinant human bone morphogenetic protein-2 (rhBMP-2) and natural latex proteins for the repair of tibial bone defects. Acta Histochem 2015;117:288-296.

46. Barbizan R, Castro MV, Ferreira RS Jr, Barraviera B, Oliveira AL. Long-term spinal ventral root reimplantation, but not bone marrow mononuclear cell treatment, positively influences ultrastructural synapse recovery and motor axonal regrowth. Int J Mol Sci 2014;15:19535-19551.

47. Câmara CN, Brito MV, Silveira EL, Silva DS, Simões VR, Pontes RW. Histological analysis of low-intensity laser therapy effects in peripheral nerve regeneration in Wistar rats. Acta Cir Bras 2011;26:12-18.

48. Fekrazad R, Eslaminejad MB, Shayan AM, et al. Effects of photobiomodulation and mesenchymal stem cells on articular cartilage defects in a rabbit model. Photomed Laser Surg 2016;34:543-549.

49. Masoumipoor M, Jameie SB, Janzadeh A, Nasirinezhad F, Soleimani M, Kerdary M. Effects of 660- and 980-nm lowlevel laser therapy on neuropathic pain relief following chronic constriction injury in rat sciatic nerve. Lasers Med Sci 2014;29:1593-1598.

50. Li Y, Zhang Y, Han W, Hu F, Qian Y, Chen Q. TRO19622 promotes myelin repair in a rat model of demyelination. Int J Neurosci 2013;123:810-822.

Address correspondence to: Rogerio Leone Buchaim

Department of Biological Sciences (Anatomy)

Bauru School of Dentistry

University of São Paulo

Al. Dr. Octávio Pineiro Brisola 9-75

Vila Nova Cidade Universitária Bauru, São Paulo CEP 17012-901

Brazil

E-mail: rogerio@fob.usp.br

Received: August 8, 2016. Accepted after revision: March 23, 2017. Published online: May 26, 2017. 